\title{
Ultrastructural Changes During Germination of Ascospores of Neurospora tetrasperma
}

\author{
By R. J. LOWR Y AND A. S. SUSSMAN \\ Department of Botany, University of Michigan, \\ Ann Arbor, Michigan, U.S.A. \\ (Accepted for publication I9 October 1967)
}

\begin{abstract}
SUMMARY
A technique is described for fixing and embedding dormant ascospores of Neurospora tetrasperma, whose impermeability has made them difficult subjects for electron microscopy. The ultrastructure of dormant and germinating spores has been compared. Endoplasmic reticulum occurs relatively infrequently in dormant ascospores whereas germinating ones have large amounts. An unusual structure, consisting of concentric membranes of varying degrees of complexity, appears after activation and disappears after extension of the germ tube. This membrane complex is continuous with the endoplasmic reticulum and may be its origin during germination. Mitochondria in dormant ascospores are larger and less numerous than in germinating ones. Two new elements of the ascospore wall are described, one of which may contribute to the relative impermeability of these forms. iNuclei increase in number during germination, but the exact number of divisions is not known.
\end{abstract}

\section{INTRODUCTION}

The ascospore of Neurospora tetrasperma is a resistant organism which can sustain itself during a long dormant period, as well as for several hours after germination, through the oxidation of endogenous substrates (Sussman, 196I). Its protoplast is enclosed in a complex wall consisting of at least three layers (Lowry \& Sussman, 1958), with a germ pore at each end of the elliptical cell. This pore appears under the light microscope to be a perforation in the outer two major wall layers which is closed by the innermost layer. Perhaps because of the very elaborate wall and associated structures, the dormant ascospore is remarkably resistant to a variety of environmental factors including extremes of temperature (Lingappa, Y. \& Sussman, I959) and toxic chemicals. For example, these spores survive after being exposed for days to the fixatives commonly used for electron microscopy (R. J. Lowry, unpublished). Upon the disruption of dormancy by heat, the metabolic capacity of ascospores is enhanced 20- to 30-fold (Goddard, 1939) and there is a shift from the oxidation of lipids alone to the rapid utilization of trehalose as well (Lingappa, B. T. \& Sussman, 1959). Several observations led us to believe that important changes at the ultrastructural level must accompany the dramatic shifts in metabolism. Thus, Holton (1960) showed that the endogenous content of cytochrome $c$ in the mitochondria of dormant ascospores was much lower than that in mitochondria of germinating spores. One possibility to explain these data is that the mitochondria change in structure during germination. Moreover, after protrusion of the germ 
tube, sensitivity to toxic substances increases markedly as does permeability (Sussman, Holton \& von Böventer-Heidenhain, 1958). These observations lead to the surmise that the ascospore wall may undergo changes which help to account for some of the events described above. Therefore, we have studied the changes in the ultrastructure of dormant and germinating ascospores in order to check these possibilities and to describe the events that occur during germination.

\section{METHODS}

Activation and germination of ascospores. Ascospores of Neurospora tetrasperma were obtained by the means described by Goddard (I935). In addition, they were incubated at $24^{\circ}$ in $0.1 \%(\mathrm{w} / \mathrm{v}$ ) EDTA at $\mathrm{pH} 7.2$ for 7 days on a reciprocal shaking machine and then washed in several changes of distilled water to ensure good reproducibility in germination. Activation was done by exposing dormant ascospores to $60^{\circ}$ for $30 \mathrm{~min}$., after which they were brought to $24^{\circ}$ and incubated on a reciprocal shaker. Germination began at about $3 \mathrm{hr}$ after activation under these circumstances.

Fixation and embedding. Germinating spores were fixed in $2 \%(\mathrm{w} / \mathrm{v})$ potassium permanganate at $4^{\circ}$ for $\mathrm{I}-2 \mathrm{hr}$. They were then washed briefly in distilled water and embedded as a concentrated suspension in $0.5 \%$ agar. The agar containing the embedded spores, cut into suitably small pieces, was dehydrated through a graded series of acetone or ethanol solutions, passed through three changes of propylene oxide and placed in a mixture of $\mathrm{I} / 3$ part Epon (Luft, I96I) $+2 / 3$ parts propylene oxide. The propylene oxide was allowed to evaporate slowly overnight, whereupon the agar blocks were transferred to pure Epon in gelatin capsules. Polymerization was done at $60^{\circ}$.

Dormant spores presented special problems because of their extreme impermeability to fixing solutions and to Epon. The procedure finally evolved was as follows. Dormant spores, suspensions in distilled water at $4^{\circ}$, were centrifuged at $3000 \mathrm{~g}$ and the pellet resuspended in a small volume of $2 \%$ potassium permanganate. A drop of the suspension was placed between a pair of 2 in. square pieces of plate glass and pressure applied with parallel-jaw glass pliers until microscopic examination showed that most of the spores had been cracked. Squeezing was repeated until enough spores were broken to form a convenient sample for embedding. The cracked spores were allowed to remain in the $2 \%$ permanganate solution at $4^{\circ}$ for $2 \mathrm{hr}$, after which they were dehydrated and embedded by the same methods as used for germinating spores. A similar technique was described by Ekundayo (1966) except that sporangiospores of Rhizopus arrhizus were broken in fixative in a Mickle disintegrator.

Sections were cut on an LKB Ultratome with either a glass or a diamond knife, mounted upon formvar-coated copper grids and sections examined in an RCA-EMU $3 \mathrm{G}$ electron microscope at $50,000 \mathrm{~V}$.

\section{RESULTS}

The spore wall

Our previous light-microscope study of the ascospore wall indicated that it is composed of three major layers including an inner layer, the endosporium, a middle layer, the episporium, and an outer layer, the perisporium $(\mathrm{C}, \mathrm{B}$ and $\mathrm{A}$, respectively 
in Pl. 2, fig. 4). Observations with the electron microscope revealed the presence of two additional layers. One of these is relatively electron-transparent and covers the ridges of the perisporium and fills in between them (arrow, Pl. 2, fig. 3, and upper arrow, Pl. 2, fig. 4). It is lamellate with a finely fibrous surface and can be sharply distinguished from the perisporium itself, which is electron-dense and, presumably, chemically distinct. The presence of this outermost layer, at least in wet spores, results in an organism with a relatively smooth surface. The outermost fibrous portion of this layer can be seen to be continuous with the fibrous outer layer of the germ tube (arrow, Pl. 3, fig. 5).

The second additional wall layer revealed by the electron microscope is composed of a very electron-dense material lying between the episporium and the endosporium (lower arrow, Pl. 2, fig. 4). The inner boundary of this layer is not sharply defined and penetrates the episporium for a short distance in the form of isolated dense granules (arrow, P1. 4, fig. 8). There appears to be an accumulation of this material at the germ pore which seems pushed out of the way by the emerging germ tube (Pl. 3, fig. 6). That this layer is associated with the endosporium is indicated by the fact that when the endosporium pulls away from the episporium, because of damage in cutting, the dense layer always remains associated with the endosporium (Pl. 2, figs. 3, 4).

\section{The protoplast of the dormant spore}

Numerous swollen mitochondria are present in dormant ascospores (Pl. I, fig. I). Attempts were made to prevent the swelling of these mitochondria by increasing the osmotic concentration of the fixing solution by adding up to $5 \%(\mathrm{w} / \mathrm{v}) \mathrm{NaCl}$, but to no avail. Otherwise the mitochondria of dormant spores appeared not to differ greatly from those of other forms (Pl. 2, fig. 3).

Dormant ascospores possess vacuoles of two types, including those of type $\mathrm{I}$, which appear empty following permanganate fixation (V I, P1. I, fig. I), and those of type 2, which contain a coarsely precipitated material (V2, P1. I, fig. I). The vacuoles are bounded by a single membrane. Only an occasional fragment of what appears to be endoplasmic reticulum is found in dormant spores (arrow, Pl. I, fig. I). The background cytoplasm appears coarse and somewhat like a flocculent precipitate (Pl. I, fig. I).

Inasmuch as the dormant spores were subjected to violent mechanical forces as a result of the methods used in fixation, it was necessary to assess the damage that may have been caused by this method of preparation. Accordingly, ascospores were activated and allowed to begin germination and were then broken in the fixative in the same manner as were dormant spores. The results are presented in Pl. I, fig. 2, and reveals that the mitochondria do not appear to be swollen. Therefore, it seems reasonable, assuming that the spores were not fixed in the few seconds that they were in the fixative before breaking, that the swollen mitochondria found in the dormant ascospore are not merely the result of mechanical damage. Germinating ascospores prepared by being broken in fixative have endoplasmic reticulum (arrows, Pl. I, fig. 2) of a type found in such spores that have not been broken (PI. 2, fig. 3). Consequently, the lack of such membranes in the dormant cracked spores seems to be a normal feature of the dormant condition and not an artifact. Moreover, the vacuoles in broken germinating and dormant ascospores appear to be alike, but the coarsely precipitated cytoplasm of the dormant ascospores does not occur to the same degree as in the cracked germinating spores. 


\section{The protoplast of the germinating spore}

The germinating ascospore contains numerous mitochondria of various shapes which are unlike the swollen ones found in the dormant spore (Pl. 2, fig. 3). Vacuoles of the two types described in the dormant ascospore also are found in germinating spores (V I, V 2, Pl. 2, fig. 3). Endoplasmic reticular membranes of a type found in material fixed in permanganate are present in the ascospore (Pl. 2, fig. 3), as well as in the germ tube (Pl. 3, fig. 6). Nuclei are present and are more numerous in sections of germinating ascospores than in those of dormant ones (Pl. 2, fig. 3). The emergence of a germ tube through a germ pore can be seen in Pl. 3, figs. 5 and 6, where the continuity of the germ tube wall and the endosporium can be seen.

In germinating ascospores from 3 to $6 \mathrm{hr}$ after activation a complex of concentric membranes that is continuous with the endoplasmic reticulum at one or more points is found. Such bodies are illustrated in sections from different spores in $\mathrm{Pl}$. 4 , figs. 7 and 8. The connexion between the outer membrane of these bodies and the endoplasmic reticulum of the spore is particularly well shown at the arrow in Pl. 4, fig. 7 . In one instance, two such bodies were noted in one section, indicating that more than one can occur in a spore. However, the frequency of their occurrence must be low, because only an occasional section is found in which they occur.

\section{DISCUSSION}

Activation of dormant ascospores of Neurospora tetrasperma triggers a series of ultrastructural as well as metabolic and physiological changes. Among the most striking is in the endoplasmic reticulum, which, although very sparse in dormant ascospores, appears in larger amounts in germinating spores. Synthesis of endoplasmic reticulum seems to be a common feature of the germination process in fungus spores, for it has been observed in most of the cases studied, including sporangiospores of Rhizopus (Hawker \& Abbott, 1963; Buckley, Sjaholm \& Sommer, I966), conidia of Botrytis cinerea (Hawker \& Hendy, 1963) and uredospores of Puccinia graminis tritici (Williams \& Ledingham, 1964). Moreover, spores of Blastocladiella emersonii also are devoid of endoplasmic reticulum, so that synthesis must occur upon their germination (Cantino, Lovett, Leak \& Lythgoe, I963).

A membrane complex, often connected to elements of the endoplasmic reticulum (Pl. 4, figs. 7, 8) is formed after activation but was not seen in germinating spores after $8 \mathrm{hr}$. Its appearance during the time of active synthesis of the endoplasmic reticulum, and its continuity with these membranes, suggests a function in the generation of the reticulum. A similar organelle may be the site of unit membrane synthesis in some animals, and consists of convolutions of endoplasmic reticulum, according to Robertson (196I). That these membrane complexes may be induced in higher plants under the stress of treatments like high doses of radiation, and anaerobiosis, has been reported by Whaley, Kephart \& Mollenhauer (1964). Moreover, anaerobically growing Torulopsis utilis forms membranous organelles (Linnane, Vitols \& Nowland, I962) which may be involved in the formation of mitochondria, because they show dehydrogenase activity. Membrane complexes also have been found in actinomycetes (Overman \& Pine, I963), hyphae of Armillaria mellae (Berliner \& Duff, 1965) and in somatic cells of Sporobolomyces (Prusso \& Wells, 1967). Therefore, membrane complexes are widely distributed and may have diverse roles. 
Another change which occurs during germination is in the size of the mitochondria in that they are very large in dormant ascospores of Neurospora tetrasperma but much smaller and more numerous in germinating spores. Whether this change in size is associated with biochemical differences like that described by Holton (I960) is not known for Neurospora but Biggs \& Linnane (1963) indicated that the cytochrome content of yeast cells and the size and organization of mitochondria were closely related. A decrease in the size of mitochondria during spore germination has been noted in a Rhizopus species (Hawker \& Abbott, 1963) and the latter authors also reported increased numbers after germination, as did Hawker \& Hendy (1963) in Botrytis cinerea conidia. This must also be the case for Blastocladiella emersonii, in whose spores only a single mitochondrion exists (Cantino et al. 1963). More cristae have been reported to be present in the mitochondria of the germ tube of the wheat stem rust than in its uredospores and their orientation is more regular as well (Williams \& Ledingham, 1964). Therefore, changes in mitochondria during the germination of fungus spores are common, at least in the relatively few cases reported. However, as Hawker \& Abbott (1963) pointed out, care must be taken to ascertain that artifacts do not arise because of the difficulties encountered in fixing and embedding fungus spores, difficulties to which we can readily attest.

That nuclear divisions occur during germination is suggested by the fact that more nuclei are seen after activation than before. It is likely that these occur before protrusion of the germ tube but their number remains to be determined.

The studies have shown that the wall of Neurospora tetrasperma ascospores consists of at least 5 distinct elements: endosporium, episporium, perisporium, a layer on the outside of the latter and one which is between the two innermost walls. The dense layer associated with the endosporium may be responsible for the relative impermeability of dormant ascospores, for it is the only layer that appears to be ruptured upon germination (arrow, Pl. 3, fig. 6). Moreover, the perisporium and episporium, being perforate at the germ pore (Lowry \& Sussman, I958), cannot act as barriers; nor does it seem likely that the endosporium acts in this way for it is continuous with the wall of the germ tube, which is readily permeable to many substances.

We gratefully acknowledge the excellent technical assistance of Miss Anne E. Harrison. This work was supported by research grants from the National Science Foundation (GB 2620) and the Rackham Fund of the University of Michigan.

\section{REFERENCES}

Berliner, M. D. \& Duff, R. H. (1965). Ultrastructure of Armillaria mellae hyphae. Can. J. Bot. 43, $17 \mathrm{I}$.

Biggs, D. R. \& Linnane, A. W. (1963). The effect of oxygen on the composition and organization of the electron transport system of yeast. Biochim. biophys. Acta 78, 785 .

Buckley, P. M., SJaholm, V. E. \& Sommer, N. F. (1966). Electron microscopy of Botrytis cinerea conidia. J. Bact. 9I, 2037.

Cantino, E. C., Lovett, J. S., Leak, L. V. \& Lythgoe, J. (I963). The single mitochondrion, fine structure, and germination of the spore of Blastocladiella emersonii. J. gen. Microbiol. $\mathbf{3} \mathbf{1}, 393$.

EKUNDAYO, J. A. (I966). Further studies on germination of sporangiospores of Rhizopus arrhizus. J. gen. Microbiol. 42, 283.

GODDARD, D. R. (1935). The reversible heat activation inducing germination and increased respiration in ascospores of Neurospora tetrasperma. J. gen. Physiol. 19, 45. 
GodDaRd, D. R. (1939). The reversible heat activation of respiration in Neurospora. Cold Spring Harb. Symp. quant. Biol. 7, 362.

HAWKeR, L. E. \& ABBOTT, P. MCV. (1963). An electron microscope study of maturation and germination of sporangio-spores of two species of Rhizopus. J. gen. Microbiol. 32, 295.

HAWKER, L. E. \& HENDY, R. J. (1963). An electron-microscope study of germination of conidia of Botrytis cinerea. J. gen. Microbiol. 33, 43.

Holton, R. W. (1960). Studies on pyruvate metabolism and cytochrome system in Neurospora tetrasperma. Plant Physiol. 35, 757.

LingaPPa, B. T. \& Sussman, A. S. (1959). Endogenous substrates of dormant, activated and germinating ascospores of Neurospora tetrasperma. Plant Physiol. 34, 466.

LingaPPA, Y. \& Sussman, A. S. (1959). Changes in the heat resistance of ascospores of Neurospora upon germination. Am. J. Bot. 46, 67I.

Linnane, A. W., Vitols, E. \& Nowland, P. G. (1962). Studies on the origin of yeast mitochondria. J. Cell Biol. 13, 345.

LOWRY, R. J. \& SUSSMAN, A. S. (1958). Wall structure of ascospores of Neurospora tetrasperma. Am. J. Bot. 45, 397.

LufT, J. H. (196I). Improvements in epoxy embedding methods. J. biophys. biochem. Cytol. 9, 409.

Overman, J. R. \& Pine, L. (1963). Electron microscopy of cytoplasmic structures in facultative and anaerobic Actinomyces. J. Bact. 86, 656.

Prusso, D. C. \& Wells, K. (1967). Sporobolomyces roseus. I. Ultrastructure. Mycologia 59, 337.

RoBertson, J. D. (196I). A new unit membrane organelle of Schwann cells. In Biophysics of Physiological and Pharmacological Action. Ed. by A. M. Shanes, no. 69, p. 63. Washington: Am. Ass. Advanc. Sci.

Sussman, A. S. (1961). The role of trehalose in the activation of dormant ascospores of Neurospora. Q. Rev. Biol. 36, I09.

Sussman, A. S., Holton, R. W. \& von Böventer-Heidenhain, B. (1958). Physiology of the cell surface of Neurospora ascospores. Entrance of anions and non-polar compounds. Arch. 29, 38 .

Whaley, W. G., Kephart, J. E. \& Mollenhauer, H. H. (1964). The dynamics of cytoplasmic membranes during development. In Cellular Membranes in Development. Ed. by M. Locke, Mikrobiol. p. 135. New York: Academic Press, Inc.

Williams, P. G. \& Ledingham, G. A. (1964). Fine structure of wheat stem rust uredospores. Can. J. Bot. 42, 1503 .

\section{EXPLANATION OF PLATES}

Electron micrographs of ascospores of Neurospora tetrasperma

Abbreviations used: A, perisporium; B, episporium; C, endosporium; ER, endoplasmic reticulum; $\mathrm{M}$, mitochondrion; $\mathrm{N}$, nucleus; $\mathrm{V}_{1}$, vacuole lacking precipitate; $\mathrm{V}_{2}$, vacuole having precipitate.

\section{Plate I}

Fig. I. Dormant ascospore showing two types of vacuoles, $\mathrm{V}_{\mathrm{I}}$ and $\mathrm{V}$ 2, and endoplasmic reticulum-like membrane at arrow. Note also the swollen mitochondria $(\mathrm{M}) .(\times 18,000$.

Fig. 2. A cracked, germinating ascospore showing typical endoplasmic reticulum (arrows), and a nucleus $(\mathrm{N})$. Vacuoles and mitochondria also are present. $(\times 14,000$. $)$

\section{Plate 2}

Fig. 3. Germinating ascospore showing wall layers, nuclei $(\mathrm{N})$, mitochondria $(\mathrm{M})$ and vacuoles. The arrow indicates the less dense component of the outer wall layer. $(\times 8000$. $)$

Fig. 4. A portion of a cross-section of a germinating ascospore showing the wall layers: perisporium (A), consisting of electron-dense ridges and a less dense component (arrow) covering the ridges and filling the space between them; episporium (B), showing characteristic features due to cutting; endosporium $(C)$, which has an extremely dense layer indicated by the arrow. $(\times 3 \mathrm{I}, 000$. 


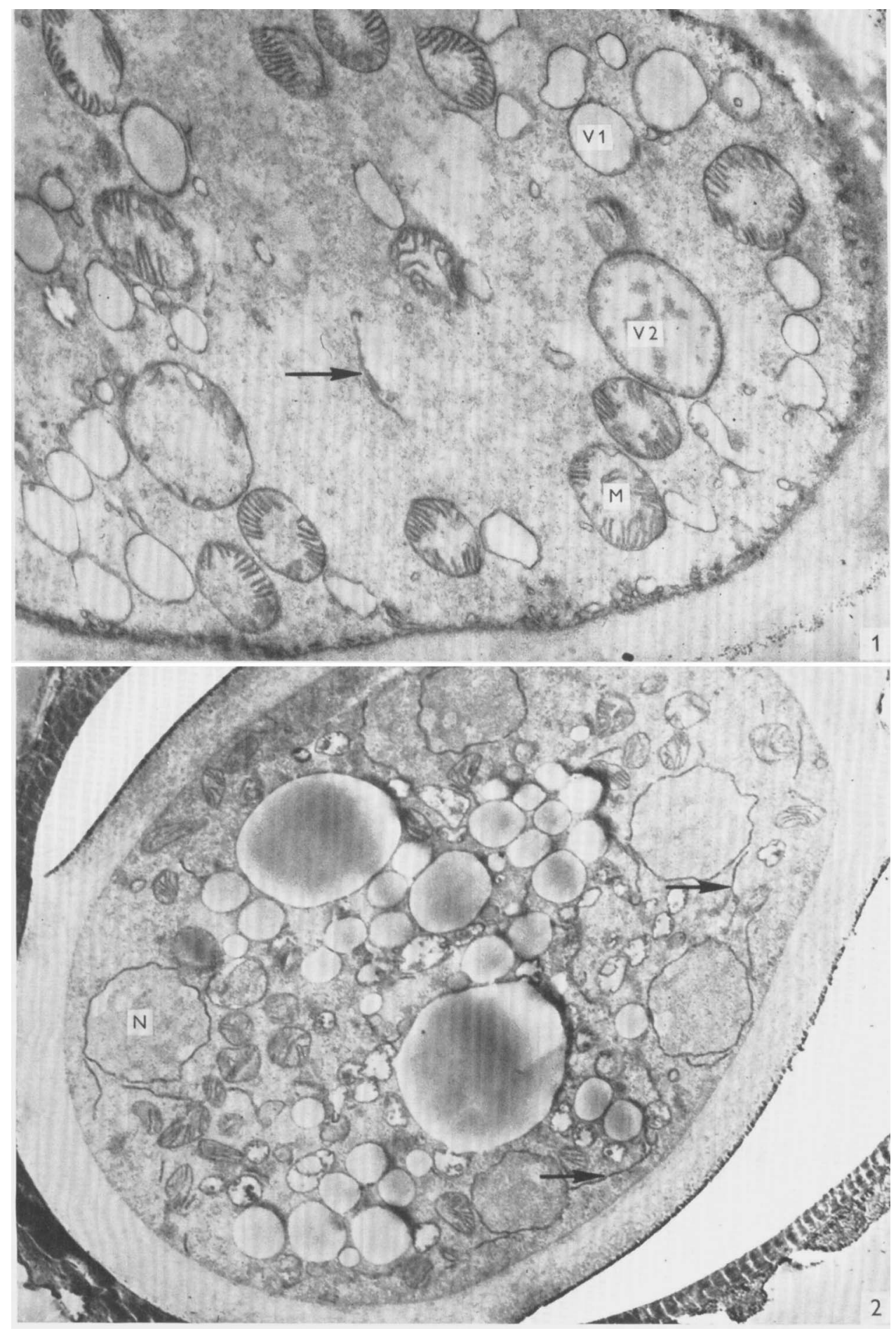




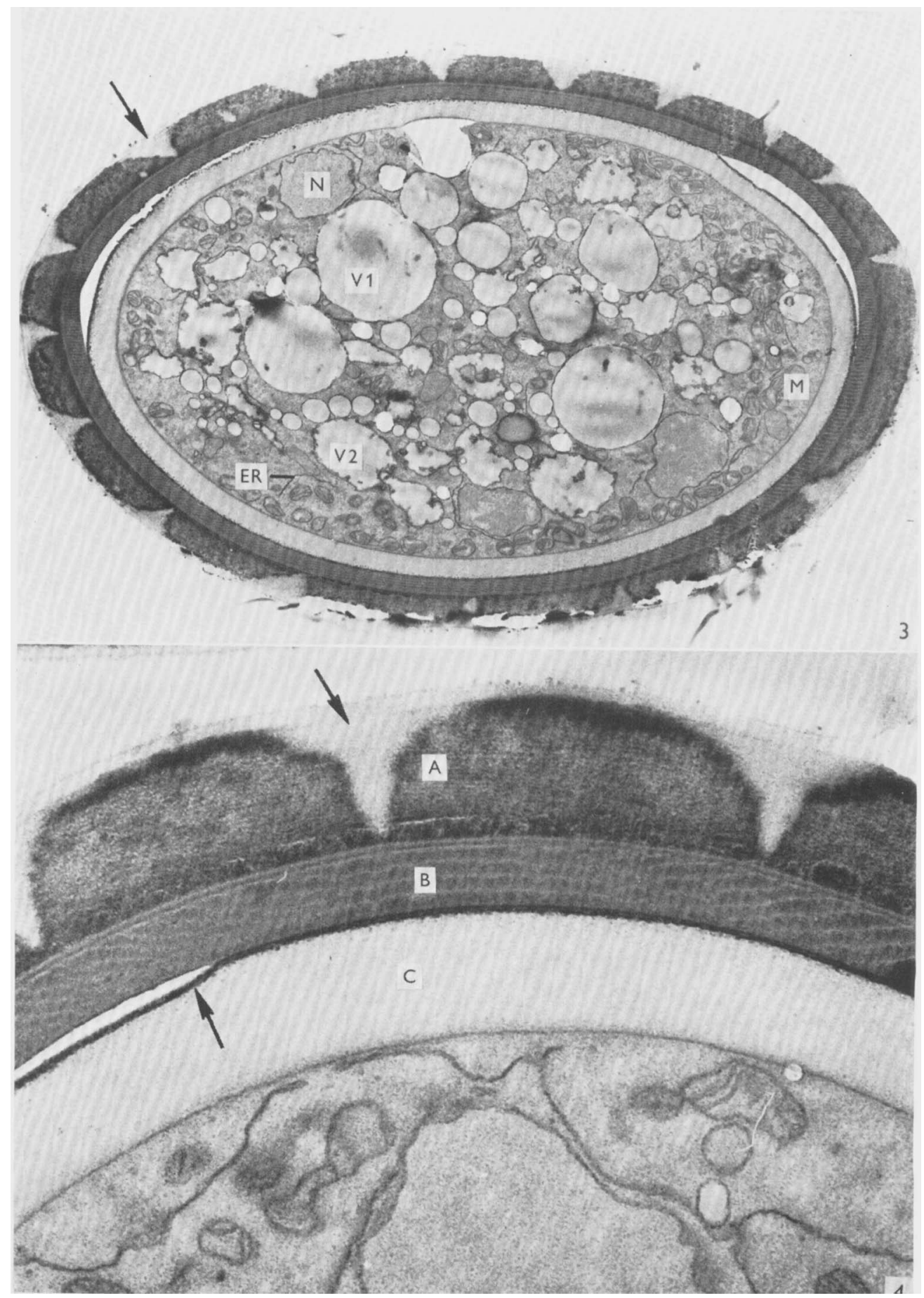

R. J. LOWRY AND A. S. SUSSMAN 
Journal of General Microbiology, Vol. 5I, No. 3

Plate 3
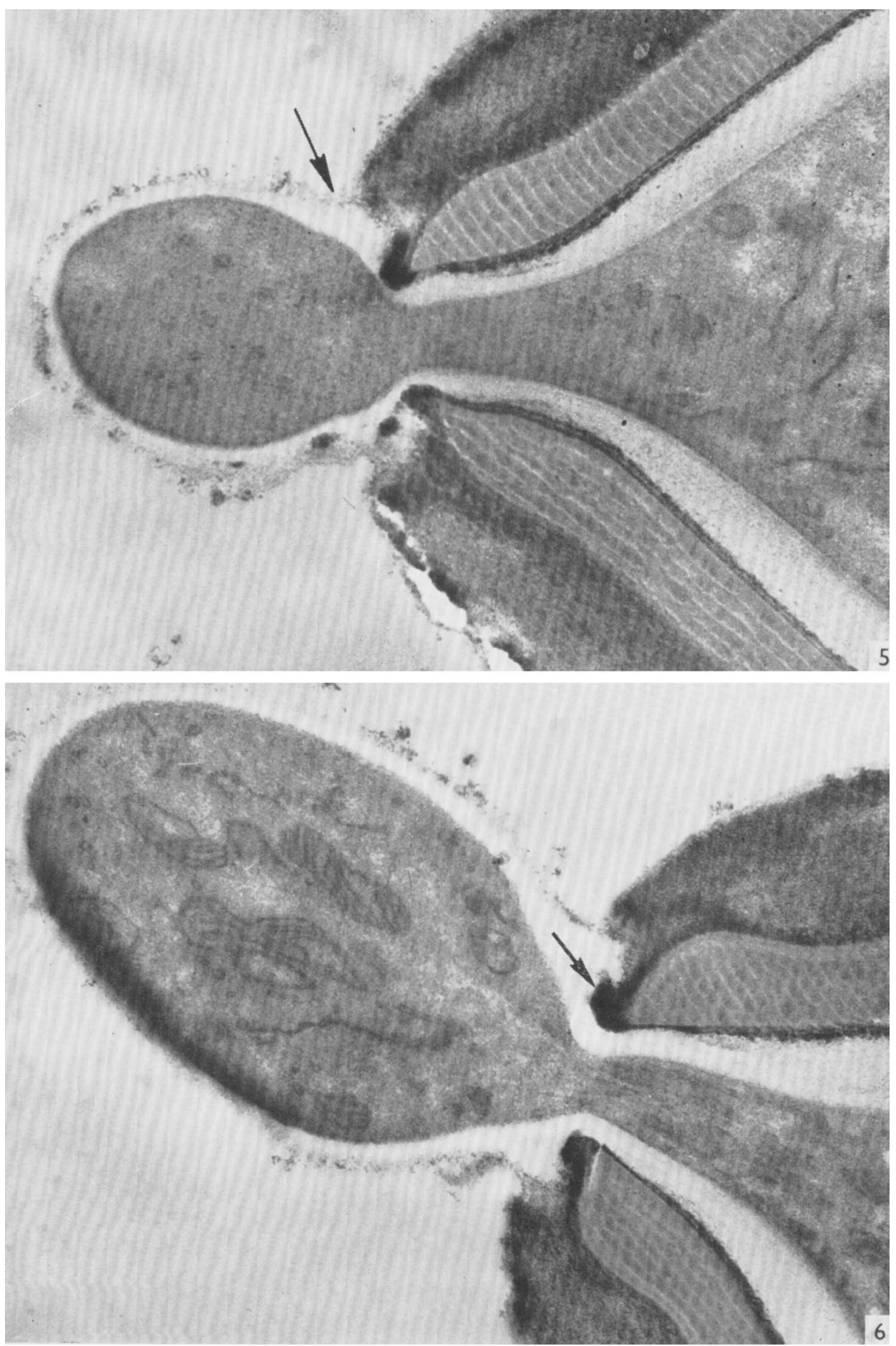

R. J. LOWRY AND A. S. SUSSMAN 

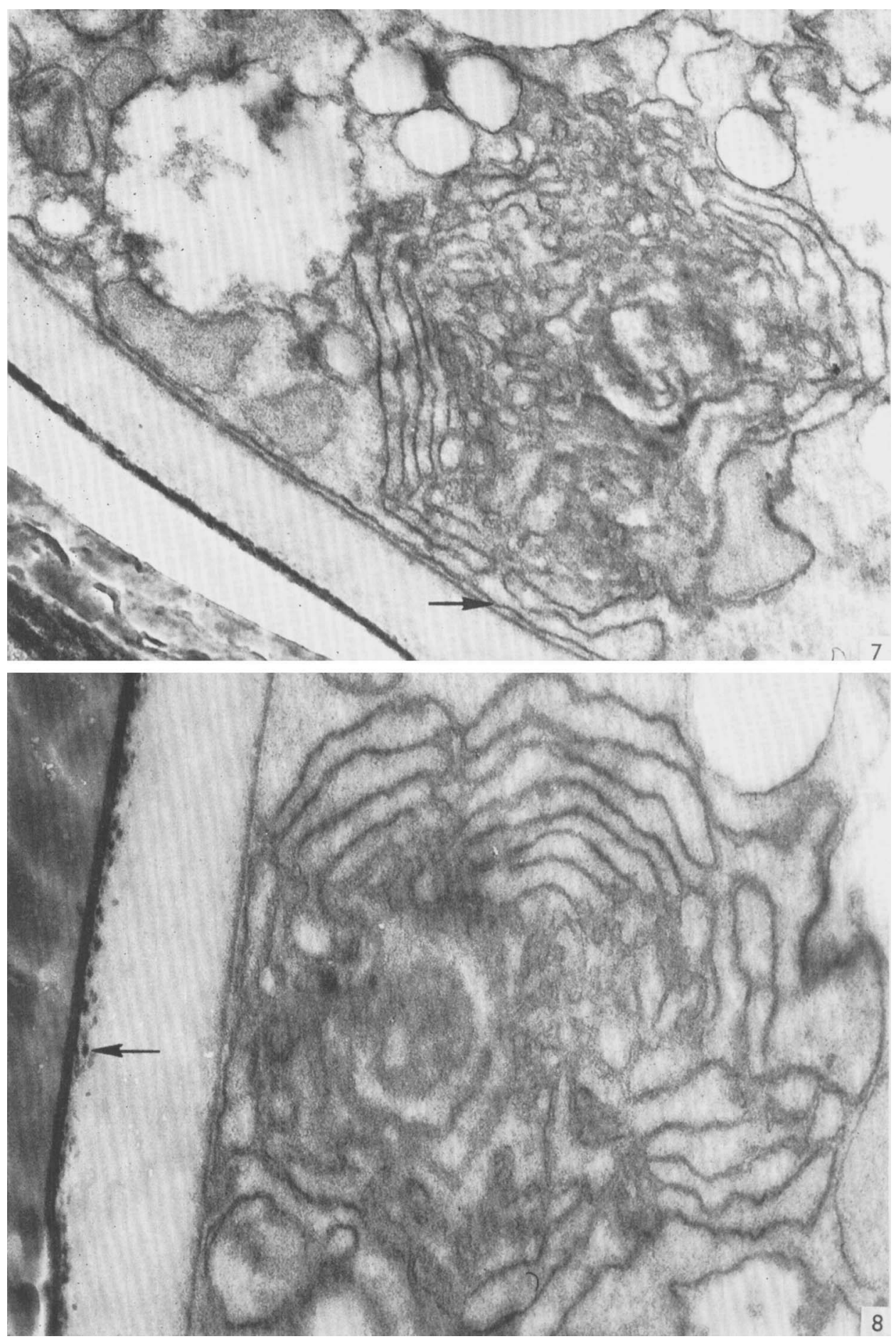

R. J. LOWRY AND A. S. SUSSMAN 


\section{Plate 3}

Fig. 5. A germinating ascospore showing the emerging germ tube and the continuity of its wall with the endosporium. The continuity of the outermost layer of the spore wall and the fibrous layer of the germ tube wall also can be seen at the arrow. $(\times 32,000$. $)$

Fig. 6. An older germ tube showing mitochondria and endoplasmic reticulum. Material which may have formed a plug in the germ pore before germination began is shown at the arrow. $(\times 32,000$.

\section{Plate 4}

Fig. 7. Ascospore in an early stage of germination, before protrusion of the germ tube. The continuity of the membrane complex and the endoplasmic reticulum is indicated at the arrow. $(\times 32,000$. $)$

Fig. 8. Ascospore in an early stage of germination, before protrusion of the germ tube. Arrow indicates the very electron-dense wall layer which occurs between the episporium and endosporium. $(\times 35,000$. 